\title{
Uso do concentrado de plaquetas em doença da superfície ocular
}

\section{Use of platelet concentrate for ocular surface disease}

Marina Soares Viegas Moura Rezende', Caroline Antunes de Almeida Silva', Victor Coronado Antunes', Luiz Eduardo Feliciano Ribeiro ${ }^{2}$, Nelson Tatsui ${ }^{3}$, Tadeu Cvintal ${ }^{4}$

\begin{abstract}
Resumo
Após uma injúria corneana, é fundamental a eliminação dos miofibroblastos a fim de garantir sua transparência. Os miofibroblastos corneanos apresentam um receptor para o fator ativador de plaquetas em sua superfície. O concentrado de plaquetas é uma das mais ricas fontes de fatores de crescimento essenciais, causando redução do sangramento, da inflamação, da escarificação, do tempo de cicatrização, acelerando assim o fechamento das úlceras.Relatamos um caso de úlcera trófica corneana não responsiva aos tratamentos convencionais e que apresentou melhora clínica significativa com colírio de concentrado de plaquetas autólogo.
\end{abstract}

Descritores: Plaquetas; Preservação de sangue; Ceratoplastia penetrante, Oftalmopatias; Relato de casos [Tipo de publicação]

\footnotetext{
'Médico do Departamento de Córnea do Instituto de Oftalmologia Tadeu Cvintal - São Paulo (SP), Brasil;

${ }^{2}$ Médico preceptor do Instituto de Oftalmologia Tadeu Cvintal - São Paulo (SP), Brasil;

${ }^{3}$ Hematologista e diretor da Criogênesis - São Paulo (SP), Brasil;

${ }^{4}$ Diretor do Instituto de Oftalmologia Tadeu Cvintal - São Paulo (SP), Brasil.

Trabalho realizado no Instituto de Oftalmologia Tadeu Cvintal - São Paulo (SP), Brasil.
}

Recebido para publicação em: 19/04/07 - Aceito para publicação em 01/08/07 


\section{INTRODUÇÃO}

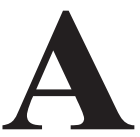
alteração neurotrófica da córnea consiste na perda da função sensorial do ramo nasociliar do nervo trigêmeo com conseqüências tais como: redução do lacrimejamento, risco aumentado de defeitos epiteliais persistentes, taxa de mitose reduzida, redução da permeabilidade e fragilidade das junções celulares $^{(1)}$.

A substância P é um neuropeptídeo presente na córnea e depletada com a denervação sensorial ${ }^{(2)}$. As neurotrofinas são uma família de polipeptídeos estrutural e funcionalmente relacionados. São expressadas em vários tecidos periféricos, controlando o desenvolvimento, a manutenção, sobrevivência e plasticidade dos neurônios periféricos. São responsáveis por diversos efeitos biológicos nos neurônios e em outras células. Foram identificados cinco tipos distintos: NGF, BDNF, NT3, $\mathrm{NT} 4 / 5$ e NT6 ${ }^{(3)}$. Animais com mutação específica para o receptor de NGF desenvolvem úlceras e mutilações dos pés, assim como opacificações corneanas ${ }^{(4)}$. A concentração do NGF está diminuída em úlceras teciduais de pacientes afetados pela diabetes mellitus, hanseníase e paralisia nervosa ${ }^{(5)}$. Experimentos têm mostrado que o NGF é armazenado e produzido em córneas normais e que após lesão epitelial, a aceleração da reepitelização está associada com o aumento dos níveis de $\mathrm{NGF}^{(6)}$.

Após uma injúria corneana é fundamental a eliminação dos miofibroblastos a fim de garantir a transparência necessária as suas funções. Os miofibroblastos corneanos apresentam um receptor para o fator ativador de plaquetas em sua superfície (como demonstrado em coelhos), como também apresentam o fator de necrose tumoral (TNF) em sua membrana. Estes fatores têm um papel importante na apoptose, causando uma opacidade corneana em conjunto com outras citoquinas ${ }^{(7)}$.

$\mathrm{O}$ concentrado de plaquetas tem sido usado em cirurgias ortopédicas e maxilo-faciais para osteogênese antes do implante de próteses; e em oftalmologia, para tamponar ampolas hiperfiltrantes em trabeculectomias em olhos hipotônicos, associado à vitrectomia posterior no tratamento de buraco macular. Um estudo demonstrou $96 \%$ de sucesso em sua resolução, com uma acuidade visual satisfatória. Na literatura, o uso em superfície ocular, para defeitos epiteliais, tem sido demonstrado até o momento, principalmente em modelo animal ${ }^{(8.9)}$.

Todavia, no encontro anual da Academia Americana de Oftalmologia de 2006 foi apresentado um estudo com seis pacientes com doença neurotrófica de superfície ocular tratados com curativo oclusivo com gel de plaquetas num disco de colágeno e antibiótico e, após melhora clínica parcial, com colírios diluídos a $25 \%$ com concentrado de plaquetas e lubrificante de $6 / 6 \mathrm{~h}$ com bons resultados ${ }^{(10)}$.

No presente estudo, relatamos um caso de úlcera trófica corneana não responsiva aos tratamentos convencionais e que apresentou melhora clínica significativa com colírio de concentrado de plaquetas autólogo.

\section{Relato de Caso}

Paciente do sexo masculino, 56 anos, branco, procedente de Penápoles-SP, se apresentou com história de cirurgia odontológica em junho de 2006, evoluindo com parestesia hemifacial direita no pós-operatório. Desenvolveu úlcera trófica no olho direito (OD) em agosto de 2006, sendo prescrito o uso de lente de contato terapêutica e ciprofloxacino tópico em outro serviço. Em 03 de janeiro de 2007, veio encaminhado com perfuração corneana central (figura 1).

Foi submetido a transplante penetrante de córnea em OD com tarsorrafia parcial temporal em 04 de janeiro de 2007. Até o sétimo dia de pós-operatório foi realizado curativo oclusivo diário e do sétimo ao décimo segundo dia de pós-operatório foi mantido o seguinte regime terapêutico: Epitezan ${ }^{\circledast} 5 \mathrm{x} / \mathrm{dia}$, Moxifloxacina $5 x /$ dia, Sulfato de Condroitina 3\% 4x/dia, Predinisolona $1 \% 4 \mathrm{x} /$ dia e lubrificante tópico sem conservantes $6 \mathrm{x} /$ dia; manteve córnea clara, com edema 1+, dobras $1+\mathrm{e}$ desepitelização de $70 \%$ da superfície corneana. Do $12^{\circ}$ até o $21^{\circ}$ dia de pós-operatório foi mantido o seguinte regime: Cloranfenicol/Dexametasona 4x/dia, Epitezan ${ }^{\oplus}$ 5x/dia, Sulfato de Condroitina 3\%, 4x/dia e lubrificante tópico sem conservantes $6 x /$ dia; não houve alteração do quadro clínico (Figura 2).

No $23^{\circ}$ pós-operatório foi iniciado colírio de concentrado de plaquetas autólogo 6x/dia associado à Moxifloxacina $4 \mathrm{x} /$ dia após o paciente ter sido orientando sobre a natureza investigativa da terapia e aprovação do Comitê de Ética.

O método de obtenção do concentrado de plaquetas foi desenvolvido a partir de trabalhos publicados anteriormente ${ }^{(11-12)}$, mas com modificações descritas a seguir com o objetivo de aumentar a concentração de plaquetas por milímetro cúbico e manter o nível de vitaminas A e E no colírio final.

Para coleta de plaquetas, utilizamos o separador celular automático Haemonetics MCS+ 9000 e o kit específico para plaqueta aférese 995-E (Haemonetics Corp.). Nesse sistema, por meio de uma punção venosa em fossa antecubital, o sangue do próprio paciente foi drenado para um dispositivo de separação. Um analisador 


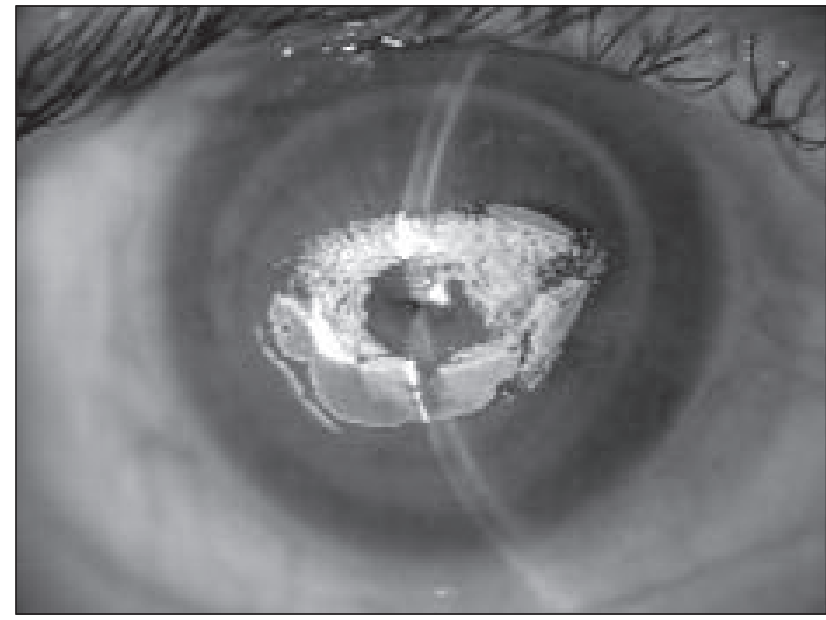

Figura 1: Perfuração cornean a pós-úlcera tró fica

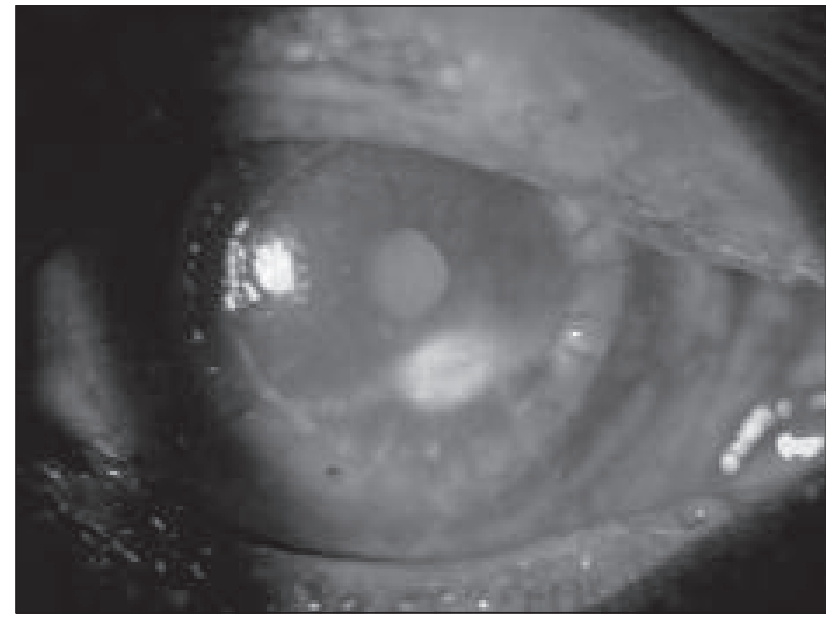

Figura 3: Melhora clínica do defeito epitelial após 5 dias de uso do colírio de concentrado de plaquetas

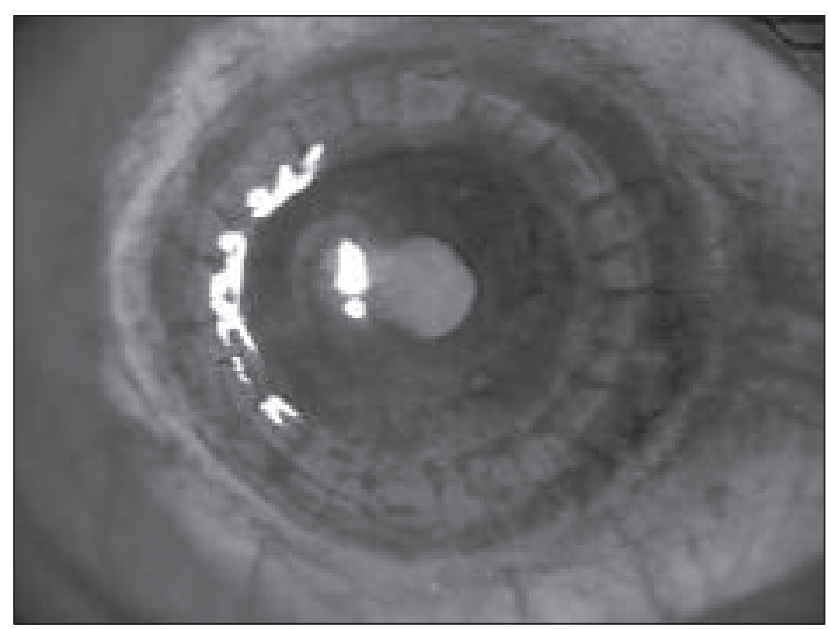

Figura 5: Melhora clínica após 17 dias de uso do colírio de concentrado de plaquetas

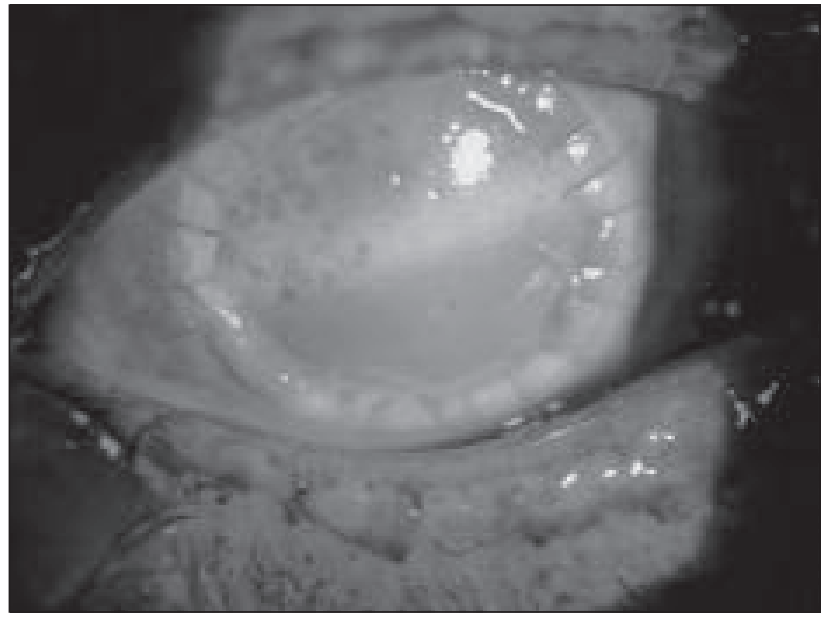

Figura 2: Defeito epitelial persistente pós-ceratoplastia penetrante

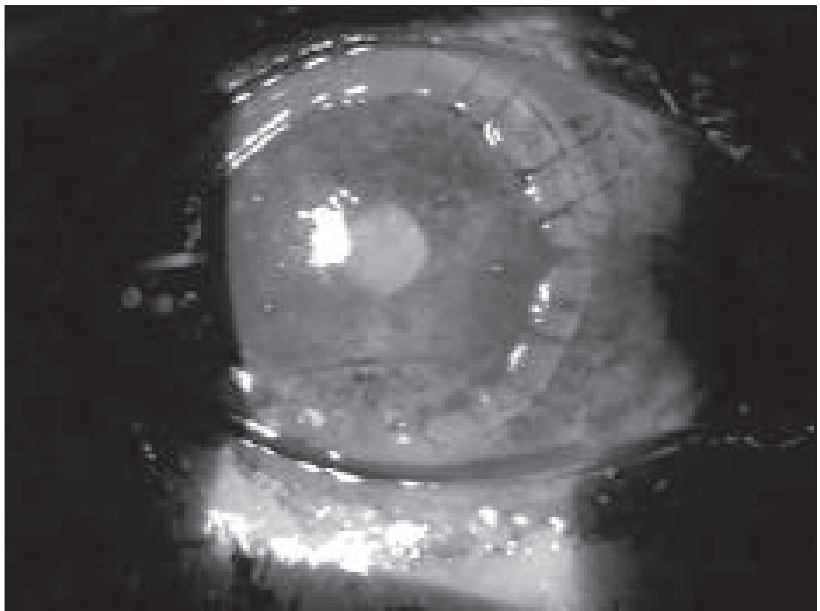

Figura 4: Melhora clínica após 8 dias de uso do colírio de concentrado de plaquetas

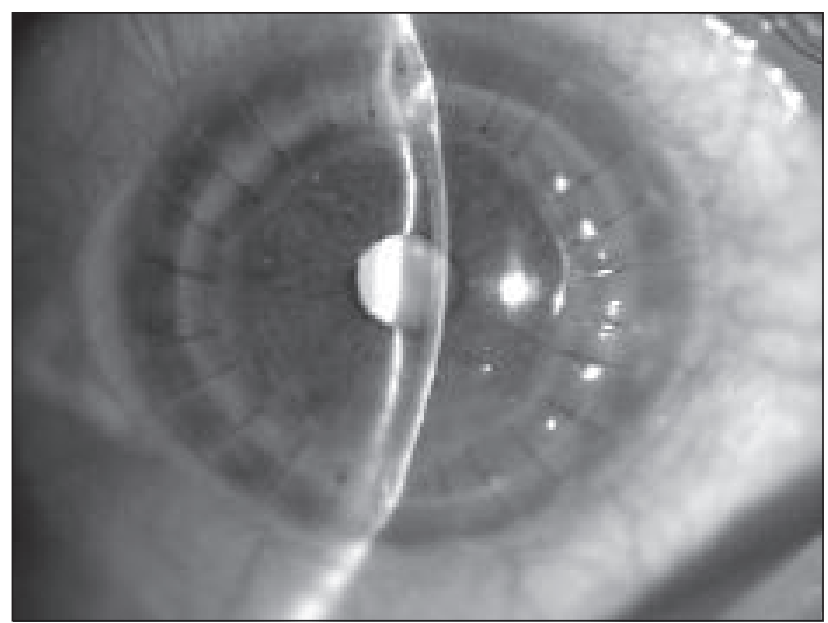

Figura 6: Melhora clínica após 17 dias de uso do colírio de concentrado de plaquetas 
Tabela 1

Índices Hematimétricos

\begin{tabular}{lccc}
\hline & Hb (g/dl) / Ht (\%) & Leucócito/mm & Plaquetas/mm \\
\hline Hemograma pós-punção & $13,8 / 41,0$ & 5800 & 185.000 \\
Hemograma após separação da camada plaquetária & $13,7 / 41,0$ & 5500 & 170.000 \\
Hemograma após preparação do concentrado de plaquetas & indetectável & Indetectável & 1.250 .000 \\
Cultura (Soro) & Não foram identificados agentes bacterianos ou fúngicos \\
\hline
\end{tabular}

de refração ótica separou a camada plaquetária e o sangue remanescente foi totalmente devolvido ao paciente, determinando o fim de um ciclo. Citrato de Sódio foi usado como anticoagulante na proporção de um para cada $9 \mathrm{ml}$ de sangue total processado. Em dois ciclos, coletamos $72 \mathrm{ml}$ de concentrado de plaquetas. Avaliamos os índices hematimétricos do paciente, antes e após o procedimento, e do concentrado de plaquetas (Coulter - ActDiff) (tabela 1).

A obtenção dos fatores de crescimento plaquetário foi feita em sala classificada, o manuseio do concentrado de plaquetas foi realizado dentro de uma cabine de segurança biológica categoria II-Tipo A. Foi acrescentado 2800 microlitros de cloreto de cálcio $10 \%$ ao concentrado de plaquetas e o produto final foi mantido a +37 graus Celsius por aproximadamente 30 minutos. Posteriormente, a unidade foi submetida à centrifugação $(900 \mathrm{~g})$ e o soro sobrenadante, que contém os fatores de crescimento plaquetário, foi transferido para 04 tubos do tipo falcon de $50 \mathrm{ml}$ (BectonDickinson) e mantido a -80 graus Celsius (Revco). Enviado amostra para pesquisa de bactérias, aeróbicas e anaeróbias, e agentes fúngicos (Bact-Alert).

A liberação do soro com fatores de crescimento plaquetário foi feita da seguinte forma: semanalmente, descongelamos 01 tubo falcon contendo aproximadamente $10 \mathrm{ml}$ de soro autólogo com fatores de crescimento plaquetário e transferimos para frascoscolírio, sendo o paciente orientado a manter o medicamento biológico em temperatura inferior a -10 graus Celsius (freezer) e descongelá-lo naturalmente imediatamente antes de cada uso.

A melhora do quadro clínico pode ser verificada na seqüência de imagens mostrando no quinto dia de uso do concentrado de plaquetas área de desepitelização de aproximadamente $3 \times 2 \mathrm{~mm}$ (figura 3). No oitavo dia de uso já apresentava epitelização completa, mas com fragilidade epitelial ainda evidente (figura 4). No $17^{\circ}$ dia de uso, já sem a tarsorrafia, apresentava epitelização total (figuras 5 e 6 ).

\section{Dıscussão}

Um grande número de fatores de crescimento tem sido encontrado no segmento ocular anterior: fator de crescimento epitelial, fator transformador do crescimento beta, fator de crescimento do ceratócito, do hepatócito, de fibroblastos, e fator de crescimento derivado de plaquetas, os quais regulam desde as mitoses celulares, diferenciação e apoptose das células corneanas ${ }^{(13)}$.

Estudos comparando elementos do plasma antes e após aférese ("serum"), demonstraram que o primeiro não oferece capacidade epiteliotrófica tão eficaz como o segundo, o qual apresenta maior teor de fator de crescimento epitelial, fator de crescimento derivado de plaquetas, fator de crescimento tumoral tipo beta $1^{(14)}$.

O concentrado de plaquetas possui fatores de crescimento úteis na epitelização corneana. Após processar este concentrado, o líquido sobrenadante possui muito mais fatores de cescimento, os quais induzem migração, estímulo e diferenciação de células epiteliais ${ }^{(12)}$.

Neste caso, o paciente não tinha respondido aos tratamentos convencionais para úlcera trófica, e optamos por tentar o concentrado de plaquetas em virtude dos benefícios acima citados com bom resultado clínico. A técnica usada nesse caso, utilizando apenas o colírio do concentrado de plaquetas, produzido conforme as técnicas explicadas, a difere da relatada anteriormente ${ }^{(10)}$, em que foi utilizada em duas apresentações diferentes (em gel e em colírio) e em concentrações diferentes. Em virtude dessas diferenças e da própria natureza dos relatos de casos possuírem poucos pacientes ainda não é possível fazer uma comparação entre as duas técnicas.

$\mathrm{O}$ fator ativador de plaquetas (PAF) tem papel mediador na inflamação e cicatrização corneana após injúrias. Em coelhos ficou evidenciado que este fator ativa o fator de crescimento endotelial vascular (VEGF), induzindo também a angiogênese ${ }^{(15)}$. Este é um lipídio bioativo que estimulado pode induzir a expressão de genes envolvidos no remodelamento da matriz extracelular como as metaloproteinases, o fator ativador 
do plasminogênio uroquinase e inibidores de metaloproteinases. Ao mesmo tempo podem proteger, ao lado de outros fatores de crescimento, os ceratócitos da apoptose ${ }^{(16)}$. A heparina então pode ser usada para reduzir as opacidades corneanas ${ }^{(17)}$.

O concentrado de plaquetas é uma das mais ricas fontes de fatores de crescimento essenciais, causando redução do sangramento, da inflamação, da escarificação, do tempo de cicatrização, assim acelerando o fechamento das úlceras.

São necessários estudos prospectivos comparando esse método às demais formas terapêuticas para confirmar os benefícios observados até agora.

\section{Abstract}

In order to assure corneal transparency after injury the effective removal of myofibroblasts is fundamental. The corneal myofibroblasts display platelet activator factor receptor on its surface. The platelet concentrate is one of the richest sources of essential growth factors, reducing bleeding, inflammation, scaring time, thus speeding up the closing of the ulcers. We report a case which provides evidence of clinical improvement with concentrate platelet eyedrops on a non responsive trophic corneal disease.

Keywords: Blood platelets; Blood preservation ; Keratoplasty, penetrating; Eye diseases; Case report [Publication type]

\section{REFERÊNCIAS}

1. Araki K, Ohashi Y, Kinoshita S, Hayashi K, Kuwayama Y, Tano Y. Epithelial wound healing in the denervated cornea. Curr Eye Res. 1994; 13(3):203-11.

2. Keen P, Tullo AB, Blyth WA, Hill TJ. Substance P in the mouse cornea: effects of chemical and surgical denervation. Neurosci Lett. 1982; 29(3):231-5.

3. Lewin GR, Barde YA. Physiology of the neurotrophins. Annu Rev Neurosci. 1996; 19: 289-317.

4. Lee KF, Li E, Huber LJ, Landis SC, Sharpe AH, Chao MV, Jaenisch R. Targeted mutation of the gene encoding the low affinity NGF receptor p75 leads to deficits in the peripheral sensory nervous system. Cell. 1992; 69(5): 737-49.

5. Anand P. Neurotrophins and peripheral neuropathy. Philos Trans R Soc Lond B Biol Sci. 1996; 351(1338):449-54. Review.
6. Kruse FE, Tseng SC. Growth factors modulate clonal growth and differentiation of cultured rabbit limbal and corneal epithelium. Invest Ophthalmol Vis Sci. 1993; 34(6): 1963-76.

7. He J, Bazan HE. Synergistic effect of platelet-activating factor and tumor necrosis factor-alpha on corneal myofibroblast apoptosis. Invest Ophthalmol Vis Sci. 2006; 47(3): 883-91.

8. Jonas JB, Dugrillon A, Klüter H, Kamppeter B. Subconjunctival injection of autologous platelet concentrate in the treatment of overfiltrating bleb. J Glaucoma. 2003; 12(1): 57-8.

9. Minihan M, Goggin M, Cleary PE. Surgical management of macular holes: results using gas tamponade alone, or in combination with autologous platelet concentrate, or transforming growth factor beta 2. Br J Ophthalmol. 1997; 81(12):1073-9.

10. Koffler B. Platelet Gel and Autologous Serum for Treating the Ocular Surface. San Francisco: American Academy of Ophthalmology Annual Meeting, 2006.

11. O’Neill EM, Zalewski WM, Eaton LJ, Popovsky MA, Pivacek LE, Ragno G, Valeri CR. Autologous platelet-rich plasma isolated using the Haemonetics Cell Saver 5 and Haemonetics MCS + for the preparation of platelet gel. Vox Sang. 2001; 81(3) 172-5.

12. Hartwig D, Harloff S, Liu L, Schlenke P, Wedel T, Geerling G. Epitheliotrophic capacity of a growth factor preparation produced from platelet concentrates on corneal epithelial cells: a potential agent for the treatment of ocular surface defects? Transfusion. 2004; 44(12):1724-31.

13. Klenkler B, Sheardown H. Growth factors in the anterior segment: role in tissue maintenance, wound healing and ocular pathology. Exp Eye Res. 2004; 79(5): 677-88.

14. Herminghaus P, Geerling G, Hartwig D, Wedel T, Dibbelt L. [Epitheliotrophic capacity of serum and plasma eyedrops. Influence of centrifugation]. Ophthalmologe. 2004; 101(10): 998-1005. German.

15. Ma X, Ottino P, Bazan HE, Bazan NG. Platelet-activating factor (PAF) induces corneal neovascularization and upregulates VEGF expression in endothelial cells. Invest Ophthalmol Vis Sci. 2004; 45(9): 2915-21.

16. Bazan $\mathrm{H}$, Ottino $\mathrm{P}$. The role of platelet-activating factor in the corneal response to injury. Prog Retin Eye Res. 2002; 21(5): 449-64.

17. Denk PO, Knorr M. Effect of heparin on human corneal fibroblast proliferation in vitro with and without growth factor stimulation. Graefes Arch Clin Exp Ophthalmol. 1999; 237(4): 342-7.

ENDEREÇO PARA CoRresPondÊnCiA:

Marina Soares Viegas Moura Rezende

Rua Manoel da Nóbrega, 753 - apto 94

São Paulo - SP

Tel: 38850735

e-mail: msvmr@bol.com.br 